\title{
Outbreak of Chikungunya Fever in Sudan, 2018-2019
}

\author{
Hassan E El Bushra ${ }^{*}$, Betigel W Habtewold ${ }^{2}$, Naeema Al Gasseer ${ }^{3}$, Rehab E Mohamed ${ }^{4}$, Salim A Mohamednour ${ }^{5}$, \\ Mazza Abshar ${ }^{6}$ and Babikir Al Magboul ${ }^{7}$
}

${ }^{1}$ Consultant Medical Epidemiologist, Khartoum, Sudan

${ }^{2}$ Public Health Consultant, World Health Organization, Sudan

${ }^{3}$ Country Representative and Head of Mission, World Health Organization, Sudan Country Office, Sudan

${ }^{4}$ Virologist, National Public Health Laboratory, Khartoum, Sudan

${ }^{5}$ National Health Coordinator, World Health Organization, Sudan

${ }^{6} \mathrm{Head}$, Communicable Disease Surveillance and Event Unit, Federal Ministry of Health, Sudan.

${ }^{7}$ Director, Health Emergency and Epidemic Control Directorate, Federal Ministry of Health, Sudan

Submission: May 20, 2019; Published: June 03, 2019

*Corresponding author: Hassan E El Bushra, Consultant Medical Epidemiologist, Khartoum, Sudan

\begin{abstract}
Introduction: During the period between 31 May 2018 and 30 March 2019, Sudan witnessed an unprecedented large outbreak of Chikungunya Fever that constituted a public health emergency of national concern.

Objective: To describe the occurrence, spread, magnitude and the responses to the outbreak; and to document lessons learned.

Material and methods: Sources of data included data from the national sentinel disease surveillance, laboratory investigation findings on the outbreak, summary of the discussions at the Emergency Operation Centres (EOC), and situation and field visit reports.

Results: The disease surveillance system reported a total of 48,763 cases of Chikungunya Fever in Sudan. Molecular characterization of the virus indicated that the Chikungunya virus was of Southeast Asian origin. Almost all cases (99.7\%) of Chikungunya Fever in the country occurred in Kassala and Red Sea States of eastern Sudan alone (19,902 and 28,861 cases respectively). Almost all cases concentrated in two major cities: Kassala City (95.5\% of all cases in Kassala State) and Port Sudan City (94.2\% of all cases in Red Sea State). Smaller outbreaks and sporadic cases of Chikungunya Fever were reported from seven other States; the sporadic cases were epidemiologically linked to the outbreak in eastern Sudan and did not result in outbreaks with locally acquired cases. Females were slightly more affected than males (51.2\% compared to $48.8 \%$ ). More than $75 \%$ of cases occurred among population aged 20-60 years.In both Kassala and Red Sea States, the Attack Rate (AR per 10,000 population) of Chikungunya Fever was consistently higher among females and the elderly; and, increased progressively with age. The AR among younger and older population showed no major difference among female and male population. Implementation of aggressive vector control measures in the affected localities in North Kordofan and West Darfur States succeeded in controlling smaller outbreak in short periods of time.
\end{abstract}

Discussion: This outbreak was the largest outbreak of Chikungunya Fever ever occurred in Africa and the Eastern Mediterranean Region. Cases showed temporal, spatial, and population aggregation during the outbreak. It is most likely that the virus entered the Sudan through a ship that harboured in Sawakin seaport. The sentinel disease surveillance system succeeded in detecting the outbreak early but grossly underestimated the actual number of cases.

Keywords: Chikungunya Fever; Outbreak; Sudan

\section{Introduction}

Chikungunya Fever is an emerging disease caused by Chikungunya Virus (CHIKV), an arbovirus transmitted by the bite of infected female mosquitoes, Aedes aegypti and Aedes albopictus [1,2]. The disease is expanding at an alarming rate across the globe [1]. Millions of Chikungunya Fever cases have been reported across more than 60 countries. In the past decade, however, Chikungunya has re-emerged in Africa, Southern and South-eastern Asia, and the Indian Ocean Islands as the cause 
of large outbreaks of human disease and Yemen in the Eastern Mediterranean Region [1-7]. Main crowded urban cities were identified as places that had high numbers of cases [1]. The disease can cause severe morbidity and, since 2005, some fatal cases were reported $[2,4]$. Sudan is a sub-Saharan African country that borders the Red Sea and seven countries. The climate in Sudan is hot and dry. In November 2018, over 200,000 people in 15 of Sudan's 18 States have been affected by heavy rains and flash floods between June and early November. The worst affected States were Kassala (47,480 people were affected), Sennar $(33,830)$, West Kordofan $(33,175)$, Gedaref $(23,975)$, Red Sea $(19,100)$, Northern $(16,450)$, Central Darfur $(14,200)$, and White Nile $(13,645)[1]$. The situation created favourable ground for mosquitoes breeding.

The prevalence of Chikungunya Fever in the general population is unknown in Sudan. Sporadic cases of Chikungunya Fever having co-infection with Yellow Fever and Dengue Fever have been reported from Sudan [1]. Four sporadic cases of Chikungunya Fever were detected during Yellow Fever outbreak in South Kordofan in 2007 [8]. A sero-prevalence survey in eastern and central Sudan found out that the sero-prevalence of Chikungunya Fever was 1.8\% [2] However, despite the reports of the sporadic cases, there were no records of occurrence of a major outbreak of Chikungunya Fever in Sudan. Nevertheless, high densities of Aedes aegypti have been detected in all States of Sudan except Khartoum and Northern States (Entomologic survey, FMOH unpublished report 2018).

On 31 May 2018, the State Ministry of Health (SMOH) of Red Sea State reported four cases of Undifferentiated Febrile Illness (UFI) associated with arthralgia and other symptoms from Sawakin locality. The diagnosis of Chikungunya Fever was initially coined based on clinical grounds and was laboratory confirmed later as the number of cases increased. On 27 July 2018, the sentinel disease surveillance system in Kassala State detected unusual increase of cases of UFI. On 8 August 2018, Kassala State reported the first suspected case of Chikungunya Fever in a male traveller from the Red Sea State. The diagnosis of Chikungunya Fever was laboratory confirmed by the National Public Health Laboratory (NPHL), Khartoum, on the same date. Afterwards, more cases were reported from Kassala city. Later, some cases of Chikungunya Fever were reported from rural areas in Kassala State. On the first week of December 2018, the Kassala State was declared free of the disease following no reports of newly diagnosed cases of Chikungunya Fever for four consecutive weeks. Nevertheless, on 09 November 2018, cases of Chikungunya Fever were reported from Red Sea State. Sporadic cases and small outbreaks of Chikungunya Fever were reported in seven other States. The last case of Chikungunya Fever in Red Sea State was reported on 30 March 2019. The main objective of this study is to describe the occurrence, spread, magnitude and the responses to the outbreak; so that, the lessons can be documented and utilized for improved preparedness and response to similar outbreaks in the future.

\section{Material and Methods}

\section{Background}

Port Sudan is the capital city of Red Sea State. It has the latitude and longitude coordinates of $19^{\circ} 37^{\prime} \mathrm{N} 37^{\circ} 13^{\prime} \mathrm{E}$. Port Sudan is the main seaport and Point of Entry (POE) for goods; Sawakin town $\left(19^{\circ} 06^{\prime} 09^{\prime \prime} \mathrm{N}, 37^{\circ} 20^{\prime} 10^{\prime}\right.$ ' E) is the main sea POE for passengers. Kassala city $\left(15^{\circ} 27^{\prime} \mathrm{N} 36^{\circ} 24^{\prime} \mathrm{E}\right)$, the capital city of Kassala State, is traversed by the seasonal Gasch River; and is famous for its fruit gardens, farms and horticulture. Jebayt $\left(18^{\circ} 57^{\prime} \mathrm{N} 36^{\circ} 50^{\prime} \mathrm{E}\right)$ is a small military-base in Red Sea State with dynamic population. It is visited by military personnel from all over the Sudan for training activities. Tokar $\left(18^{\circ} 25^{\prime} \mathrm{N} 037^{\circ} 43^{\prime} \mathrm{E}\right)$ is a town in Red Sea State that lies in the delta of the seasonal Baraka River. In the whole world, only 48 locations are warmer than Tokar, and 166 are dryer [2].

\section{Case Definition}

The Federal Ministry of Health (FMOH) and World Health Organization (WHO) developed case definitions for Chikungunya Fever. A suspected case of Chikungunya Fever is defined as a person presented with acute onset of fever (greater than $38.5^{\circ} \mathrm{C}$ ) and severe arthralgia with travel history to areas affected by Chikungunya Fever transmission within 15 days prior to the onset of symptoms and his/her illness could not be explained by other medical conditions. A confirmed case of Chikungunya Fever is defined as a suspected case with laboratory confirmation by one of the following two tests in the acute phase: Serological tests, such as Enzyme-Linked Immunosorbent Assays (ELISA), to confirm the presence of IgM and IgG anti-chikungunya antibodies and or presence of viral RNA by Reverse TranscriptasePolymerase Chain Reaction (RT-PCR) as recommended by WHO [2].

The Health Care Workers (HCWs) were trained on the case definitions. The case definitions were printed in posters and were distributed to all public and private health facilities in the affected States. At the peak of the outbreak, the SMOH instructed all health facilities and private practitioners to report suspected cases of Chikungunya Fever on daily basis including zero reports.

\section{Laboratory Investigation}

More than one hundred-fifty blood samples were collected from suspected cases of Chikungunya Fever from the affected States and were sent to the NPHL, Khartoum, Sudan for testing by RT-PCR and or ELISA to confirm diagnosis. Additional laboratory tests were made to exclude malaria and Dengue Fever. The sequencing of the virus was conducted to identify the strain of the outbreak and determine the Chikungunya lineage. 


\section{Sources of Data}

The investigators used the national disease surveillance data, active surveillance (zero reporting), and laboratory investigation findings. This study incorporated major findings from situation and field visit reports submitted by FMOH, Rapid Response Teams (RRT), and the WHO teams deployed to the affected States during the course of the outbreak. In addition, the study made use of unpublished reports and summary of the discussions during taskforce meetings that took place at the Emergency Operation Centres (EOC) in FMOH and SMOH in Kassala and Red Sea States, and the WHO Country Office, Sudan.

\section{Analysis of Data}

The collected data were used to produce epidemic curves that show the pattern of transmission of the outbreak. Geography Information System (GIS) was used to develop series of maps that displayed the dynamics of the outbreak. Excel software was used to draw graphs, calculate age, sex-specific Attack Rates (AR) by State and mean + Standard Deviation (SD) of cases by age and sex distribution.

\section{Control Measures Instituted during the Outbreak}

The key interventions instituted by $\mathrm{FMOH} / \mathrm{SMOH}$ to contain the spread of the outbreak centred on four areas. The control measures included: enhancing disease surveillance, improving case management (including use of bed nets), implementing Integrated Vector Control (IVC) and intensifying social mobilization. More than $67 \mathrm{UN}$, international and national organizations, societies and institutions participated in the planning, implementation and coordination of response measures under the leadership of the $\mathrm{FMOH} / \mathrm{SMOH}$. In addition, volunteers and local communities took part in the field operations. The government provided stewardship in coordinating the response activities at national and State level. The WHO and United Nations Children's Fund (UNICEF), with the generous donations from United Nations Office for the Coordination of Humanitarian Affairs (UNOCHA), Italian Cooperation and USAID/OFDA, provided technical, logistical and financial support to the FMOH, SMOH and health partners to respond to the outbreak. The SMOH in Red Sea State liaised with seaport authorities in Port Sudan in expediting the process of clearance of customs and other formalities for Sudanese religious visitors returning from Saudi Arabia after performing Umra to reduce their vulnerability to Chikungunya infection in Sawakin town.

\section{Results}

\section{Epidemiologic Description of the Outbreak}

The sentinel disease surveillance system in Sudan reported a total of 48,763 cases of Chikungunya Fever during the period between 31 May 2018 and 30 March 2019. Almost all cases
(99.7\%) of Chikungunya Fever in the country occurred in Kassala and Red Sea States of eastern Sudan alone. In eastern Sudan, the outbreak occurred in four waves. The alert for the first wave of the outbreak that occurred in Sawakin town, Red Sea State (736 cases) was on 31 May 2018. The outbreak in Sawakin town continued for nine weeks. The onset of symptoms of the suspected Chikungunya Fever cases started on 23 May 2018. The diagnosis of Chikungunya Fever was confirmed by the NPHL in Khartoum on 31 May 2018. Molecular characterization of the virus indicated that the CHIKV was of Southeast Asian origin (unpublished report, FMOH). The majority of patients in Sawakin town were treated as outpatients; only $2 \%$ of patients were admitted to the hospital. The second wave of the outbreak occurred in Kassala State where the sentinel disease surveillance system reported a total of 19,902 cases of Chikungunya Fever. Almost all cases $(19,015$ cases, $95.5 \%$ of all cases in Kassala State) occurred in Kassala City alone.

The daily caseload reached as high as 1,100 cases during the peak of the outbreak. The epidemic curve of Chikungunya Fever in Kassala was bimodal (with two peaks); the outbreak continued for 11 weeks. Smaller outbreaks occurred in two localities around Kassala City; namely, Rural Kassala (636 cases) and West Kassala (251 cases). The first laboratory confirmed case of Chikungunya Fever from Kassala State was a 26 years old male who had a travel history to the Red Sea State; symptoms started on the 27 July 2018. The last case of Chikungunya Fever was reported from Kassala State on 19 October 2018. The third wave started on 16 September 2018 in Port Sudan, Red Sea State. The outbreak in Port Sudan continued for 20 weeks in single long wave. A total of 28,861 cases were reported throughout the course of the outbreak. Port Sudan City alone reported $94.2 \%$ of all cases in Red Sea State. The last case was reported on 30 March 2019. The fourth wave of the outbreak occurred in Sawakin town $(1,129$ cases, $3.9 \%$ of all cases in Red Sea State) during the period between 09 December 2018 to 24 March 2019. The outbreak occurred for the second time in Sawakin town in concurrence with the third wave in Port Sudan City. There were smaller outbreaks reported from two other neighboring localities in Red Sea State; namely, Jebayt (Sinkat locality) and Tokar. In Jebayt town (201 cases, $0.7 \%$ of all cases in Red Sea State) occurred on 18 September 2018 amid the outbreak in Kassala State; and later moved to Tokar locality in Red Sea State (344 cases, 1.2\%).

Figure 1 shows distribution of Chikungunya Fever in Kassala and Red Sea State by locality. Figure 2 shows the epidemic curve of the major and small outbreak in Sudan. As depicted in the epidemic curve, the incubation period was about 10 days. Figures $3 \& 4$ show the monthly progressive spread of Chikungunya Fever from one quarter of the city to another in Kassala and Port Sudan Cities i.e. temporal, spatial, and density distribution of cases. 

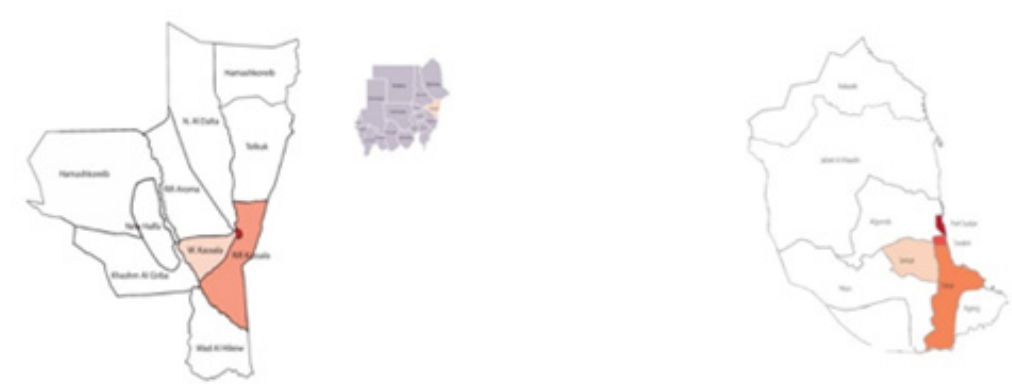

Figure 1: Distribution of Chikungunya Fever in Kassala and Red Sea State by locality.

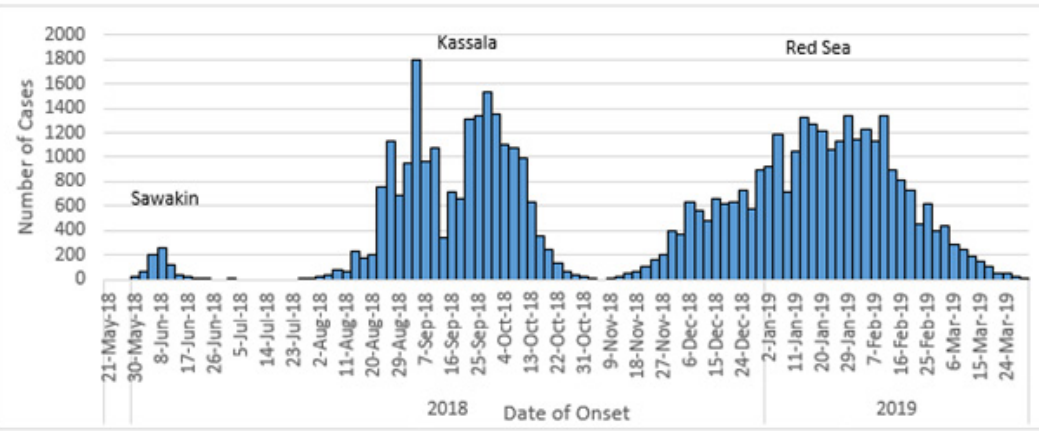

The first graph shows three waves of the outbreak in Sawakin, Kassala and Red Sea.

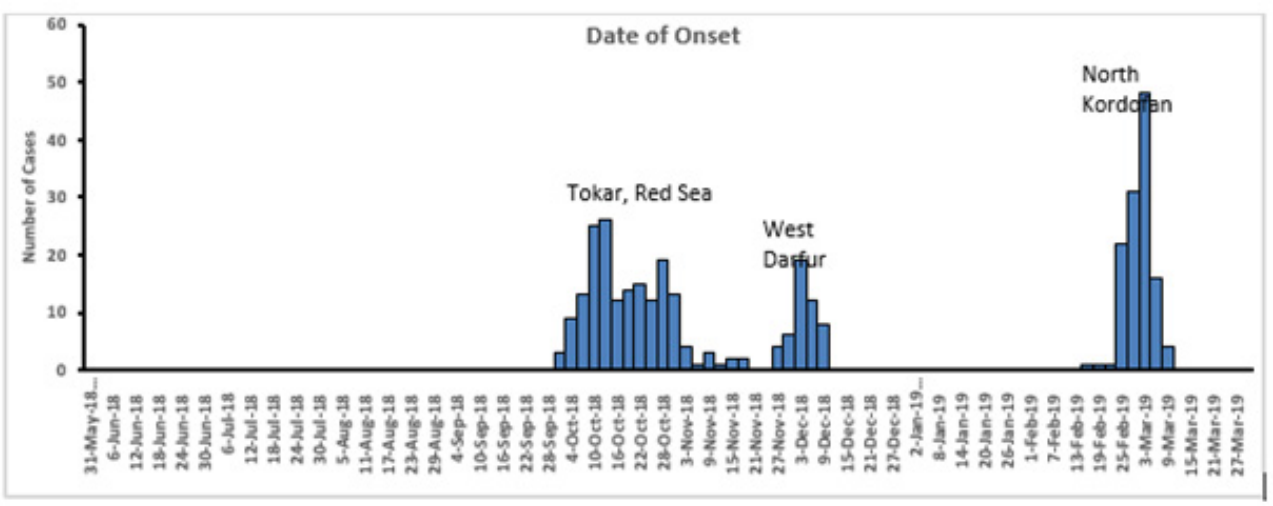

The second graph shows the three waves in Tokar, West Darfur and North Kordofan.

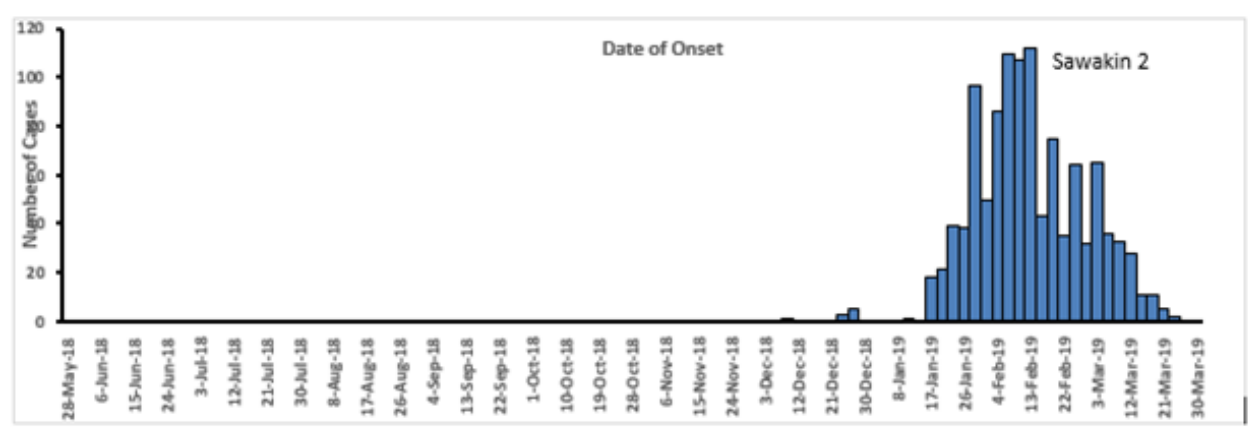

The third graph shows the last wave of the outbreak in Sawakin (for second time).

Figure 2 


\section{Juniper Online Journal of Public Health}
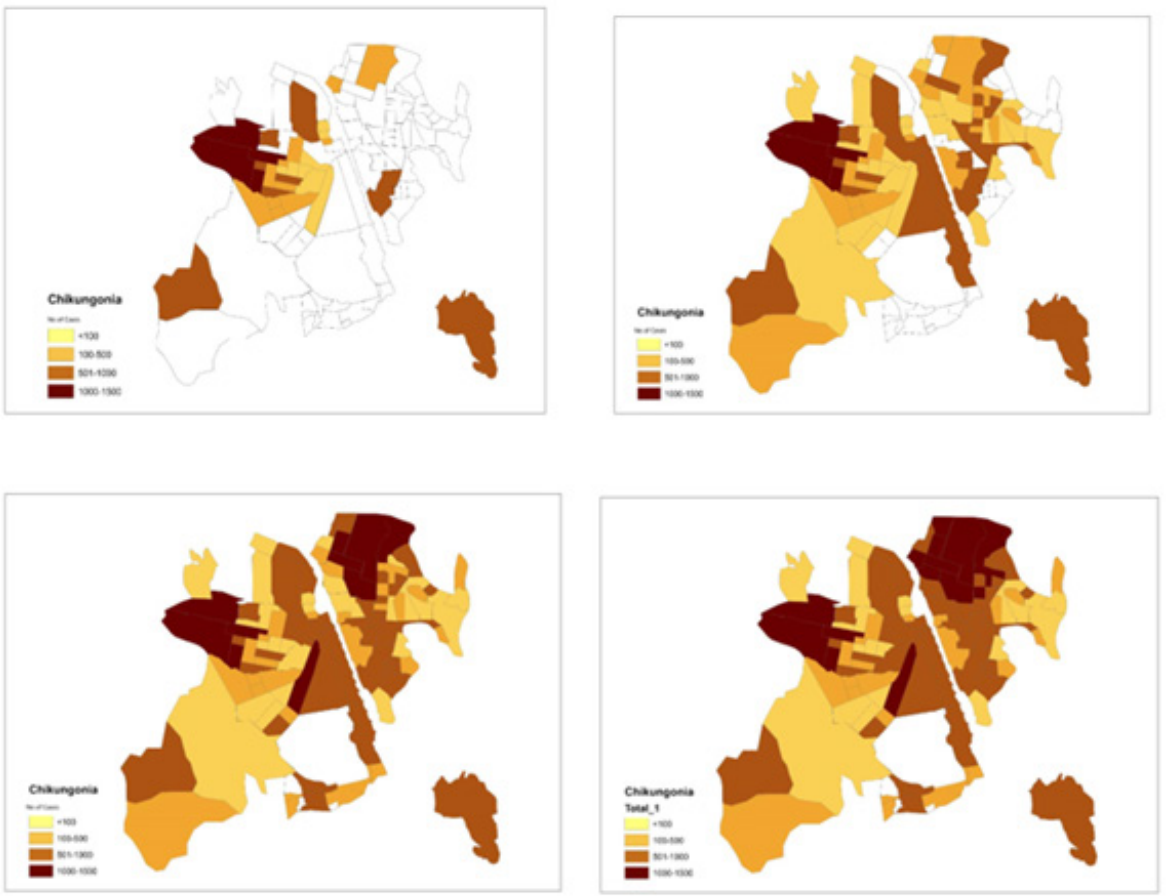

Map (A): Period between 22 July 2018 and 12 August 2018;

Map (B): Period between 22 July 2018 and 9 September 2018;

Map (C): Period between Period between 22 July 2018 and 7 October 2018; and

Map (D): Period between Period between 22 July 2018 and 7 October 2018

Figure 3: Showing spread of Chikungunya Fever in Kassala City.
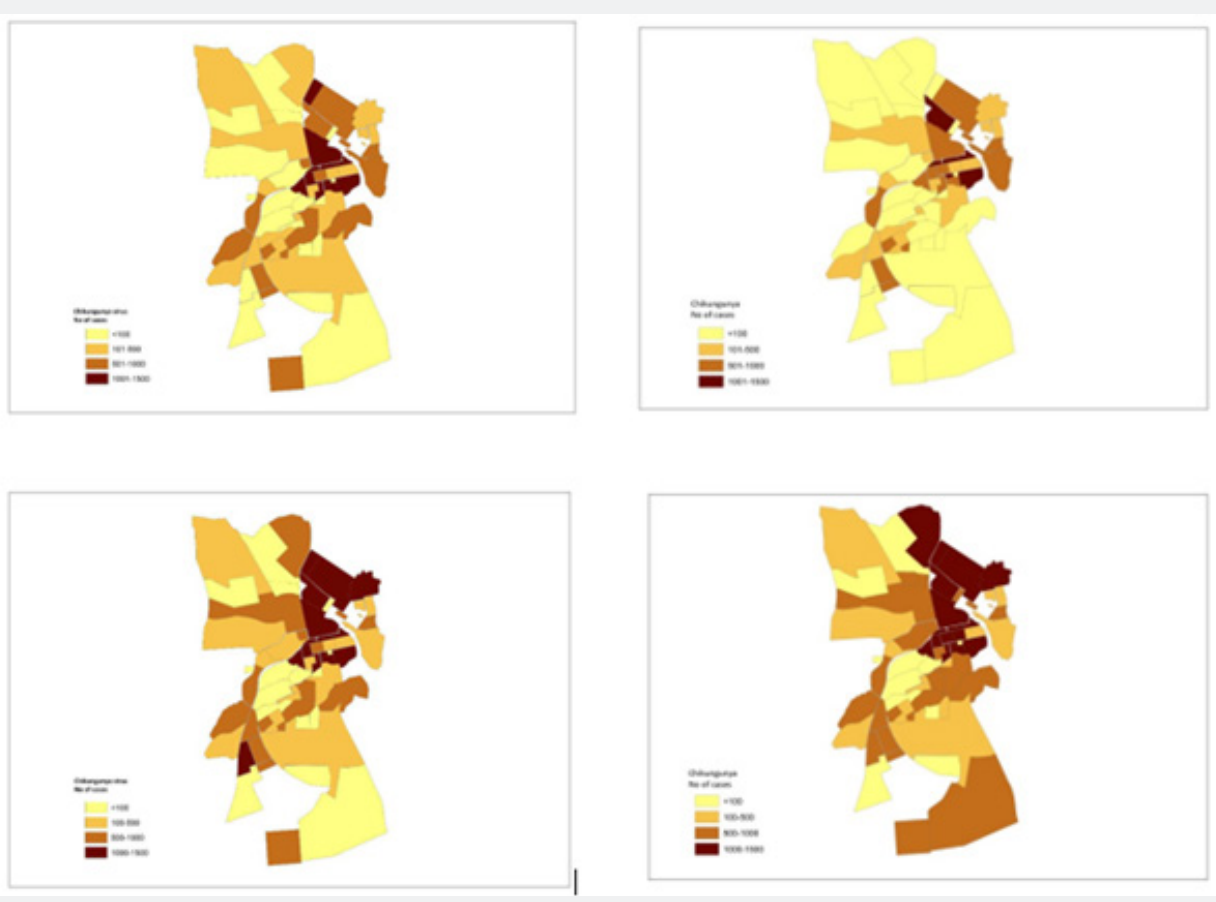

Map (A): Period between 9 November 2018 and 6 December 2018 Map (B): Period between 9 November 2018 and 11January 2018

Map (C): Period between 9 November 2018 and 16 February 2019

Map (D): Period between 9 November 2018 and 24 March 2019

Figure 4: Showing spread of Chikungunya Fever in Port Sudan City. 
Smaller outbreaks and laboratory-confirmed sporadic cases of Chikungunya Fever were also reported from seven other States in Sudan; namely, Gedaref, River Nile, Gezira, Sennar, South Darfur, West Darfur and North Kordofan. All the reported sporadic cases were laboratory-confirmed and epidemiologically linked to the outbreak in eastern Sudan. The sporadic cases did not result in outbreaks with locally acquired cases, except in West Darfur and North Kordofan States. In West Darfur 39 locally acquired cases of Chikungunya Fever were documented. In North Kordofan a small outbreak (113 cases) occurred in small village (Um Janah Khalil village, Um Damm locality) during the period between 26 February 2019 and 16 March 2019. The outbreak was successfully contained, and no more cases of Chikungunya Fever were reported from neighbouring towns or villages in North Kordofan.

\section{Age-sex Distribution of Chikungunya cases}

The Chikungunya Fever affected all age groups. Table 1 shows the mean age of reported cases by sex in the two affected

Table 1: Mean age of Chikungunya cases in Kassala and Red Sea State.

\begin{tabular}{|c|c|c|c|c|c|}
\hline State & Sex & $\mathbf{N}$ & Mean & Standard Deviation (SD) & Inter Quartile Range (IQR) \\
\hline \multirow{3}{*}{ Kassala } & Male & 8,556 & 28.4 & 18.7 & $13-40$ \\
\hline & Female & 11,317 & 29.3 & 17.6 & $15-40$ \\
\hline & Total & 19,873 & 28.9 & 18.1 & $14-40$ \\
\hline \multirow{3}{*}{ Red Sea } & Male & 14,086 & 31.3 & 19.3 & $18-45$ \\
\hline & Female & 14,775 & 32.3 & 18 & $15-45$ \\
\hline & Total & 28,861 & 31.9 & 18.7 & $17-45$ \\
\hline
\end{tabular}

Table 2: Age Sex Distribution of Chikungunya Cases in Kassala State by Locality, 2018, Sudan.

\begin{tabular}{|c|c|c|c|c|c|}
\hline \multirow{3}{*}{ Age Group } & \multirow{3}{*}{ Sex } & \multicolumn{4}{|c|}{ Locality } \\
\hline & & Kassala City & Rural Kassala & West Kassala & Total \\
\hline & & N (\%) & N (\%) & N (\%) & N (\%) \\
\hline \multirow{3}{*}{ Less than 5} & Male & $562(50.4)$ & $19(47.5)$ & $3(37.5)$ & $584(50.2)$ \\
\hline & Female & $553(49.6)$ & $21(52.5)$ & $5(62.5)$ & $579(49.8)$ \\
\hline & Total & 1,115 & 40 & 8 & 1,163 \\
\hline \multirow{3}{*}{$5-9.9$} & Male & $786(48.4)$ & $33(50.8)$ & $3(100.0)$ & $822(48.6)$ \\
\hline & Female & $839(51.6)$ & $32(49.2)$ & $0(0.0)$ & 871 (51.4) \\
\hline & Total & 1,625 & 65 & 3 & 1,693 \\
\hline \multirow{3}{*}{$10-19.9$} & Male & $1,962(46.5)$ & $57(51.4)$ & $16(50.0)$ & 2035 (46.7) \\
\hline & Female & $2,254(53.5)$ & $54(48.6)$ & $16(50.0)$ & $2324(53.3)$ \\
\hline & Total & 4,216 & 111 & 32 & 4,359 \\
\hline \multirow{3}{*}{$20-29.9$} & Male & $1,344(38.6)$ & $48(34.5)$ & $14(21.5)$ & $1,406(38.1)$ \\
\hline & Female & $2,140(61.4)$ & $91(65.5)$ & $51(78.5)$ & $2,282(61.9)$ \\
\hline & Total & 3,484 & 139 & 65 & 3,688 \\
\hline \multirow{3}{*}{$30-39.9$} & Male & $1,216(39.2)$ & $41(36.9)$ & $20(30.8)$ & $1,277(39.0)$ \\
\hline & Female & $1,884(60.8)$ & $70(63.1)$ & $45(69.2)$ & $1,999(61.0)$ \\
\hline & Total & 3,100 & 111 & $65(100.0)$ & 3,276 \\
\hline \multirow{3}{*}{$40-49.9$} & Male & 976 (39.7) & $39(47.6)$ & $15(40.5)$ & $1,030(39.9)$ \\
\hline & Female & $1,485(60.3)$ & $43(52.4)$ & $22(59.5)$ & $1,550(60.1)$ \\
\hline & Total & 2,461 & 82 & 37 & 2,580 \\
\hline
\end{tabular}

States. Tables $2 \& 3$ show the frequency distribution of Chikungunya Fever by locality in Kassala and Red Sea States. The overall mean age in years $(+\mathrm{SD})$ of cases was $28.9(+18.1)$ and 31.9 (+ 18.7) for Kassala and Red Sea States. Generally, females were slightly more affected than males (51.2\% compared to $48.8 \%)$; the female to male sex ratio ranged between 1.1: 1 and 1.3:1. e outbreak affected all age groups; more than $75 \%$ of cases urred among population aged 20-60 years. About $14.3 \%$ of cases occurred among population aged less than 20 years; nly $8 \%$ of the cases occurred among the elderly (60 years A per 10,000 population) of Chikungunya cases was conprogres that led to management of cases of Chikungunya Fever without using them at health facilities and household levels. The news of the outbreak was widely shared in the social media throughout the outbreak. 


\begin{tabular}{|c|c|c|c|c|c|}
\hline \multirow{3}{*}{$50-59.9$} & Male & $631(42.3)$ & $139(35.1)$ & $6(35.3)$ & $650(42.0)$ \\
\hline & Female & 861 (57.7) & $24(64.9)$ & 11 (64.7) & $896(58.0)$ \\
\hline & Total & 1,492 & 37 & 17 & 1,546 \\
\hline \multirow{3}{*}{60 and more } & Male & $726(47.7)$ & $25(49.0)$ & $16(66.7)$ & 767 (48.0) \\
\hline & Female & $796(52.3)$ & $26(51.0)$ & $8(33.3)$ & $830(52.0)$ \\
\hline & Total & 1,522 & 51 & 24 & 1,597 \\
\hline \multirow{3}{*}{ Total } & Male & $8,203(43.1)$ & $275(43.2)$ & 93 (37.1) & $8,571(43.1)$ \\
\hline & Female & $10,812(56.9)$ & $361(56.8)$ & $158(62.9)$ & 11,331 (56.9) \\
\hline & Total & 19,015 & 636 & 251 & 19,902 \\
\hline
\end{tabular}

Table 3: Age Sex Distribution of Chikungunya Cases in Red Sea State by Locality, 2019, Sudan.

\begin{tabular}{|c|c|c|c|c|c|c|}
\hline \multirow{3}{*}{ Age Group } & \multirow{3}{*}{ Sex } & \multicolumn{4}{|c|}{ Localities } & \multirow{2}{*}{ Total (Red Sea) } \\
\hline & & Sawakin $(2) *$ & Sinkat & Port Sudan & Tokar & \\
\hline & & N (\%) & N (\%) & N (\%) & N (\%) & N (\%) \\
\hline \multirow{3}{*}{ Less than 5} & Male & $18(50.0)$ & $3(33.3)$ & 427 (53.9) & $1(50.0)$ & $449(53.5)$ \\
\hline & Female & $18(50.0)$ & $6(66.7)$ & $365(46.1)$ & $1(50.0)$ & $390(46.5)$ \\
\hline & Total & 36 & 9 & 792 & 2 & 839 \\
\hline \multirow{3}{*}{$5-9.9$} & Male & $42(50.6)$ & $20(60.6)$ & $1,082(54.8)$ & 15 (78.9) & 1,159 (54.9) \\
\hline & Female & $41(49.4)$ & 13 (39.4) & $894(45.2)$ & $4(21.1)$ & $952(45.1)$ \\
\hline & Total & 83 & 33 & 1,976 & 19 & 2,111 \\
\hline \multirow{3}{*}{$10-19.9$} & Male & $121(49.8)$ & $40(55.6)$ & $3,010(54.1)$ & $56(57.7)$ & $3,227(54.0)$ \\
\hline & Female & $122(50.2)$ & $32(44.4)$ & $2,549(45.9)$ & $41(42.3)$ & $2,744(46.0)$ \\
\hline & Total & 243 & 72 & 5,559 & 97 & 5,971 \\
\hline \multirow{3}{*}{$20-29.9$} & Male & $112(53.6)$ & 18 (58.1) & $2,159(46.7)$ & $25(48.1)$ & $2,314(47.1)$ \\
\hline & Female & $97(46.4)$ & 13 (41.9) & 2,467 (53.3) & 27 (51.9) & $2,604(52.9)$ \\
\hline & Total & 209 & 31 & 4626 & 52 & 4,918 \\
\hline \multirow{3}{*}{$30-39.9$} & Male & $125(55.1)$ & $9(42.9)$ & $2,043(42.7)$ & $29(44.6)$ & $2,206(43.3)$ \\
\hline & Female & $102(44.9)$ & $12(57.1)$ & $2,739(57.3)$ & $36(55.4)$ & 2,889 (56.7) \\
\hline & Total & 227 & 21 & 4,782 & 65 & 5,095 \\
\hline \multirow{3}{*}{$40-49.9$} & Male & $81(49.1)$ & 7 (41.2) & $1,679(41.4)$ & $34(53.1)$ & $1,801(41.9)$ \\
\hline & Female & $84(50.9)$ & 10 (58.8) & 2,372 (58.6) & $30(46.9)$ & $2,496(58.1)$ \\
\hline & Total & 165 & 17 & 4,051 & 64 & 4,297 \\
\hline \multirow{3}{*}{$50-59.9$} & Male & $48(42.5)$ & $6(60.0)$ & $1,434(48.5)$ & $22(70.9)$ & $1,510(48.6)$ \\
\hline & Female & $65(57.5)$ & $4(40.0)$ & $1,522(51.5)$ & 9 (29.1) & $1,600(51.4)$ \\
\hline & Total & 113 & 10 & 2,956 & 31 & 3,110 \\
\hline \multirow{3}{*}{60 and more } & Male & $34(64.2)$ & $5(62.5)$ & 1,371 (56.1) & $10(62.5)$ & $1,420(56.3)$ \\
\hline & Female & $19(35.8)$ & $3(37.5)$ & $1,072(43.9)$ & $6(37.5)$ & $1,100(43.7)$ \\
\hline & Total & 53 & 8 & 2,443 & 16 & 2,520 \\
\hline \multirow{3}{*}{ Total } & Male & $581(51.5)$ & $108(53.7)$ & $13,205(48.6)$ & $190(55.2)$ & $14,086(48.8)$ \\
\hline & Female & $548(48.5)$ & $93(46.3)$ & $13,980(51.4)$ & $154(44.8)$ & $14,775(51.2)$ \\
\hline & Total & 1129 & 201 & 27,185 & 344 & 28,861 \\
\hline
\end{tabular}


Table 4: Shows the Attack Rate (AR) per 10,000 population in both Kassala and Red Sea.

\begin{tabular}{|c|c|c|c|c|c|c|c|c|c|c|}
\hline \multirow{2}{*}{ Age Group } & \multirow{2}{*}{ Sex } & \multicolumn{3}{|c|}{ Kassala } & \multicolumn{3}{|c|}{ Port Sudan } & \multicolumn{2}{|c|}{ Both States } & \multirow[b]{2}{*}{ AR } \\
\hline & & Population & No. of cases (\%) & AR & Population & No. of cases (\%) & AR & Population & No. of cases (\%) & \\
\hline \multirow{3}{*}{ Less than 5} & Male & $1,40,007$ & $584(50.2)$ & 42 & 82,371 & $449(53.5)$ & 55 & $2,22,378$ & 1,033 (51.6) & 46 \\
\hline & Female & $1,34,207$ & 579 (49.8) & 43 & 78,959 & $390(46.5)$ & 49 & $2,13,166$ & $969(48.4)$ & 45 \\
\hline & Total & $2,74,214$ & $1,163(5.8)$ & 42 & $1,61,330$ & $839(2.9)$ & 52 & $4,35,544$ & $2,002(4.1)$ & 46 \\
\hline \multirow{3}{*}{ 5-9.9 } & Male & $1,27,018$ & $822(48.6)$ & 65 & 74,729 & $1,159(54.9)$ & 155 & $2,01,747$ & $1,981(52.1)$ & 98 \\
\hline & Female & $1,22,195$ & $871(51.4)$ & 71 & 71,892 & $952(45.1)$ & 132 & $1,94,086$ & $1,823(47.9)$ & 94 \\
\hline & Total & $2,49,213$ & $1,693(8.5)$ & 68 & $1,46,621$ & $2,111(7.3)$ & 144 & $3,95,833$ & $3,804(7.8)$ & 96 \\
\hline \multirow{3}{*}{$10-19.9$} & Male & $2,16,450$ & 2,035 (46.7) & 94 & $1,27,345$ & 3,227 (54.0) & 253 & $3,43,796$ & $5,262(50.9)$ & 153 \\
\hline & Female & $2,09,212$ & $2,324(53.3)$ & 111 & $1,23,087$ & $2,744(46.0)$ & 223 & $3,32,299$ & $5,068(49.1)$ & 153 \\
\hline & Total & $4,25,663$ & 4,359 (21.9) & 102 & $2,50,432$ & $5,971(20.7)$ & 238 & $6,76,095$ & $10,330(21.2)$ & 153 \\
\hline \multirow{3}{*}{$20-29.9$} & Male & $1,59,454$ & $1,406(38.1)$ & 88 & 93,813 & $2,314(47.1)$ & 247 & $2,53,267$ & $3,720(43.2)$ & 147 \\
\hline & Female & $1,55,661$ & $2,282(61.9)$ & 147 & 91,581 & $2,604(52.9)$ & 284 & $2,47,242$ & $4,886(56.8)$ & 198 \\
\hline & Total & $3,15,116$ & $3,688(18.5)$ & 117 & $1,85,394$ & $4,918(17.0)$ & 265 & $5,00,509$ & $8,606(17.6)$ & 172 \\
\hline \multirow{3}{*}{$30-39.9$} & Male & $1,17,241$ & 1,277 (39.0) & 109 & 68,977 & $2,206(43.3)$ & 320 & $1,86,218$ & $3,483(41.6)$ & 187 \\
\hline & Female & $1,16,094$ & $1,999(61.0)$ & 172 & 68,302 & $2,889(56.7)$ & 423 & $1,84,396$ & $4,888(58.4)$ & 265 \\
\hline & Total & $2,33,335$ & $3,276(16.5)$ & 140 & $1,37,279$ & 5,095 (17.7) & 371 & $3,70,613$ & $8,371(17.2)$ & 226 \\
\hline \multirow{3}{*}{$40-49.9$} & Male & 79,372 & $1,030(39.9)$ & 130 & 46,697 & $1,801(41.9)$ & 386 & $1,26,069$ & $2,831(41.2)$ & 225 \\
\hline & Female & 80,580 & $1,550(60.1)$ & 192 & 47,408 & 2,496 (58.1) & 526 & $1,27,987$ & $4,046(58.8)$ & 316 \\
\hline & Total & $1,59,951$ & $2,580(13.0)$ & 161 & 94,105 & 4,297 (14.9) & 457 & $2,54,056$ & 6,877 (14.1) & 271 \\
\hline \multirow{3}{*}{$50-59.9$} & Male & 48,990 & $650(42.0)$ & 133 & 28,823 & $1,510(48.6)$ & 524 & 77,813 & $2,160(46.4)$ & 278 \\
\hline & Female & 51,195 & $896(58.0)$ & 175 & 30,120 & $1,600(51.4)$ & 531 & 81,314 & $2,496(53.6)$ & 307 \\
\hline & Total & $1,00,185$ & $1,546(48.0)$ & 154 & 58,942 & $3,110(10.8)$ & 528 & $1,59,127$ & $4,656(9.5)$ & 293 \\
\hline \multirow{3}{*}{$60-69$} & Male & 28,748 & $767(48.0)$ & 267 & 16,913 & $1,420(56.3)$ & 840 & 45,661 & 2,187 (53.1) & 479 \\
\hline & Female & 30,783 & $830(52.0)$ & 270 & 18,110 & $1,100(43.7)$ & 607 & 48,893 & $1,930(46.9)$ & 395 \\
\hline & Total & 59,530 & $1,597(8.0)$ & 268 & 35,024 & $2,520(8.7)$ & 720 & 94,554 & $4,117(8.4)$ & 435 \\
\hline \multirow{3}{*}{ TOTAL } & Male & $9,34,169$ & $8,571(43.1)$ & 92 & $5,49,604$ & $14,086(48.8)$ & 256 & $14,83,773$ & $22,657(46.5)$ & 153 \\
\hline & Female & $9,19,341$ & $11,331(56.9)$ & 123 & $5,40,880$ & $14,775(51.2)$ & 273 & $14,60,221$ & $26,106(53.5)$ & 179 \\
\hline & Total & $18,29,308$ & $19,902(100.0)$ & 109 & $10,76,245$ & $28,861(100.0)$ & 268 & $29,05,553$ & $48,763(100.0)$ & 168 \\
\hline
\end{tabular}

\section{Discussion}

\section{Magnitude of the outbreak}

There are reasonable grounds that suggest the magnitude of the outbreak might have been grossly underestimated. This could be explained by the limitations of the sentinel surveillance system, home treatment, and under reporting of cases. The outbreak was detected by the sentinel disease surveillance system. Although the sentinel surveillance is good in detecting outbreaks early; however, it is not designed to capture all cases of the disease of interest. Hence, the number of cases detected by the sentinel surveillance system does not show the actual number of cases.

Private clinics were not initially reporting suspected cases of Chikungunya Fever. The health authorities in Kassala directed all private practitioners, private and public health facilities to submit daily reports including zero-reporting of cases of Chikungunya Fever; albeit, this action was initiated relatively late during the outbreak. There were no indicators to show how initiation of active surveillance was successful in capturing all Chikungunya Fever cases that visited private health facilities. It has been observed that people opted home and self-treatment because they knew that there was no specific medication to cure for viral diseases and that Chikungunya Fever is not fatal. Some families might have relied on home treatment due to the cost of treatment at hospitals as there could be many patients from the same household.

Therefore, a sero-survey or a carefully designed cluster survey using appropriate tools would provide a better estimate of the magnitude of the outbreak. Such information are needed for preparedness and better planning for similar event in future. It is conceivable that a conservative educated estimate indicate that the number of Chikungunya Fever cases during this outbreak may be four- or five-fold larger than the reported cases i.e. the number of actual cases may range between 200,000 to 250,000 cases in the two most affected States, Kassala and Red Sea. 


\section{Juniper Online Journal of Public Health}

This study documents not only the largest outbreak of an epidemic-prone disease ever reported in Sudan, but also the largest outbreak of Chikungunya Fever ever occurred in Africa and the Eastern Mediterranean Region (EMR). The sentinel disease surveillance system in Sudan reported a total of 48,763 cases of Chikungunya Fever that occurred within 10 months. The recent countrywide outbreak of Acute Watery Diarrhea (AWD) that continued for two years (2016-2018) affected about 36,962 people in Sudan [2]. The outbreak of meningococcal meningitis of 1999 affected 33,312 people in Sudan [3]. The first outbreak of Chikungunya Fever in EMR occurred in 2010-2011 in Al-Hudaydah, Yemen, and affected about 15,000 people [9]. The major epidemic of Chikungunya Fever in Réunion Island in 2005-2006 reported a total of 244,000 cases [4].

The feeding behaviour of Aedes aegypti which requires multiple human bites before oviposition increases the likelihood of infecting more people; and thus, would further escalate transmission of the virus. Failure of infected persons to use bed nets at home and in health facilities as part of case management protocol could have amplified the transmission among copatient, health workers, household contacts and people living in neighbouring houses. There are no statistical data about the occurrence of cases of Chikungunya Fever among Health Care Workers (HCW). Yet, anecdotal reports attested occurrence of more cases of Chikungunya Fever among HCW. This may warrant further study to assess the increased number of cases attributable to limited use of bed net as part of standard case management protocol. The sharp increase of Chikungunya Fever cases in Kassala City transformed the situation into a public health emergency of national concern. The social media amplified the public panic to the degree that brought higher officials, including His Excellency the Prime Minister, Federal State Ministry of Health, Undersecretary and Parliamentarians to Kassala State. The high-profile visit to the affected communities, an indicator for political will and commitment, was instrumental in boosting up control measures.

\section{Index Case}

The results of the outbreak investigation revealed that the first laboratory confirmed case (index case) of Chikungunya Fever outbreak in Sudan was from Sawakin, Red Sea State. It is most likely that the virus entered the Sudan through a ship that harbored in Sawakin seaport. Moreover, the case investigation showed that the first diagnosed case in Kassala gave history of travel to Sawakin town with in the incubation period of Chikungunya Fever. Unlike the outbreak in Sawakin town, the outbreak of Chikungunya Fever in Kassala was highly publicized nationwide due to its magnitude and rapid spread; the social media played pivotal role in disseminating its occurrence. Travelers infected with Chikungunya fever contributed to wider spread of outbreaks elsewhere [5-8]. Preventing the movement of symptomatic individuals was found to be an insufficient mechanism to halt the spread of the disease as sub-clinical individuals may do spread the disease [6].

\section{Age-sex Distribution}

The surveillance data showed that Chikungunya Fever affected equally all age groups except for females aged 20-60 years. This is relatively consistent with the findings from the 2006 Chikungunya outbreak in South India where the AR were higher among persons $>15$ years of age and females in both urban and rural settings $[10,11]$. Most studies showed equal or slight increase in the proportion of females [7-8]. The higher AR of Chikungunya Fever among females and elderly shown in this study could probably be explained by the fact that females and the elderly tend to stay at home during the day close to household mosquito breeding sites. Aedes aegypti bites primarily during the day as it is most active for approximately two hours after sunrise and several hours before sunset when people are unlikely to put on protective clothes, use repellent or bed nets [12]. The high attack rate suggests that the infection was new to this area. Absence of human population immunity correlated with a large chikungunya fever outbreak [13]. Chikungunya virus can cause explosive outbreaks with substantial morbidity. Given the increasing globalization of chikungunya virus, strong surveillance systems and access to laboratory testing are essential to detect outbreaks [14]. Timely sharing of the index cases is therefore highly recommended to control the spread and magnitude of the outbreak [15].

\section{Co-Infections}

Chikungunya Fever having co-infection with Dengue Fever and Yellow Fever is well documented in Sudan and elsewhere $[16,17]$. During an outbreak of haemorrhagic fever occurred in South Kordofan in 2005, Sudan, IgM antibodies to chikungunya virus were detected in five (27\%) ill persons and three (19\%) asymptomatic persons which indicated that both Chikungunya and Yellow Fever occurred during the outbreak [15]. In eastern Sudan, the occurrence of co-infections with Dengue Fever virus and or malaria could not be ruled out; especially, there were documented small outbreaks of Dengue Fever and increased incidence of malaria in Kassala and Red Sea States in the past decade. Both Dengue Fever and malaria share some of the clinical presentations of Chikungunya Fever; e.g., fever, headache and joint pains [15-19]. As Dengue Fever and Chikungunya Fever share the same clinical signs and are transmitted by the same vector, there is a risk of misdiagnosis in the affected areas as both diseases have co-distribution of virus and vector. In addition, coinfections of these diseases are common and can have fatal outcomes if left undiagnosed. The co-circulation of arboviruses that are transmitted by the same vectors pose a public health threat and is likely to cause misdiagnosis and underreporting of Chikungunya Fever in areas where Dengue Fever has been reported; e.g., Port Sudan; and warrants implementation of routine testing of both Chikungunya and Dengue virus in suspected patients for better patient management [20-24].

\section{Refrences}

1. Gould LH, Osman MS, Farnon EC, Griffith KS, Godsey MS, et_al. (2008) An outbreak of yellow fever with concurrent chikungunya virus 
transmission in South Kordofan Sudan 2005. Transactions of the Royal Society of Tropical Medicine and Hygiene 102(12): 1247-54.

2. Al-Gasseer N, El Bushra HE, Yeneabat A, et al. (2019) Countrywide Outbreak of Acute Watery Diarrhea in Sudan, 2016 - 2018. EC Emergency Medicine and Critical Care 3.5: 274-284.

3. International Federation of Red Cross and Red Crescent Societies (ICRC). Sudan: Meningitis, Disaster Relief Emergency Fund (DREF) Bulletin, 27 April 2007. Accessed on 21 April 2019.

4. Renault P, Solet JL, Sissoko D, Balleydier E, Larrieu S, et_al. (2007) A major epidemic of chikungunya virus infection on Reunion Island, France, 2005-2006. Am J Trop Med Hyg 77(4):727-731.

5. Delisle E, Rousseau C, Broche B, Leparc-Goffart I, L'Ambert G, et al. (2015) Chikungunya outbreak in Montpellier, France, September to October 2014. Euro Surveill 20(17): pii: 21108.

6. Dommar CJ, Lowe R, Robinson M, Rodo X (2014) An agent-based model driven by tropical rainfall to understand the spatio-temporal heterogeneity of a chikungunya outbreak. Acta Trop 129: 61-73.

7. Kaur P, Ponniah M, Murhekar MV, Ramachandran V, Ramachandran R, et_al. (2008) Chikungunya outbreak, south India, 2006. Emerging infectious diseases 14(10):1623-1625.

8. Adam A, Seidahmed OM, Weber C, Schnierle B, Schmidt-Chanasit J, et al. (2016) Low Sero-prevalence Indicates Vulnerability of Easternand Central Sudan to Infection with Chikungunya Virus. Vector Borne Zoonotic Dis 16(4): 290-291.

9. Borgherini G, Poubeau P, Staikowsky F, Lory M, Le Moullec N, et_al. (2007) Outbreak of chikungunya on Reunion Island: early clinical and laboratory features in 157 adult patients. Clin Infect Dis 44(11): 14011407.

10. Peters CM, Pijnacker R, Fanoy EB, Bouwman LJ, de Langen LE, et al. (2018) Chikungunya virus outbreak in Sint Maarten: Long-term arthralgia after a 15-month period. J Vector Borne Dis 55(2): 137-143.

11. Manimunda SP, Sugunan AP, Rai SK, Vijayachari P, Shriram AN, et_al. (2010) Outbreak of chikungunya fever, Dakshina Kannada District, South India, 2008. The American journal of tropical medicine and hygiene 83(4): 751-754.

12. (2018) Centres for Disease Control and Prevention (CDC) Dengue and the Aedes aegypti mosquito.
13. Panning M, Wichmann D, Grywna K, Annan A, Wijesinghe S, et_al. (2009) No evidence of chikungunya virus and antibodies shortly before the outbreak on Sri Lanka. Med Microbiol Immunol 198(2): 103-106.

14. Pastula DM, Hancock WT, Bel M, Biggs H, Marfel M, et_al. (2017) Chikungunya virus disease outbreak in Yap State, Federated States of Micronesia. PLoS Negl Trop Dis; 11(3): e0005410.

15. Staples JE, Breiman RF, Powers AM (2009) Chikungunya fever: an epidemiological review of a re-emerging infectious disease. Clinical infectious diseases 49(6): 942-948.

16. Tokar (2019) Sudan, Wikipedia.

17. Farnon EC, Gould LH, Griffith KS, Osman MS, Kholy AE (2010) Household-based sero-epidemiologic survey after a yellow fever epidemic, Sudan, 2005. The American journal of tropical medicine and hygiene $82(6): 1146-52$.

18. Deilgat M, Geduld J, Drebot M (2014) Chikungunya Outbreak in the Caribbean 2013-2014. Can Commun Dis Rep 40(2): 7-12.

19. Qiaoli Z, Jianfeng H, De W, Zijun W, Xinguang Z, et_al. (2012) Maiden outbreak of chikungunya in Dongguan city, Guangdong province, China: epidemiological characteristics. PLoS One 7(8): e42830.

20. Kabir I, Dhimal M, Müller R, Banik S, Haque U (2017) The 2017 Dhaka chikungunya outbreak. Lancet Infect Dis 17(11): 1118.

21. Ratsitorahina M, Harisoa J, Ratovonjato J, Biacabe S, Reynes JM, et_al. (2008) Outbreak of dengue and Chikungunya fevers, Toamasina, Madagascar, 2006. Emerging infectious diseases 14(7): 1135-1137.

22. Kaur N, Jain J, Kumar A, Narang M, Zakaria MK, et_al. Chikungunya outbreak in Delhi, India, 2016: report on coinfection status and comorbid conditions in patients. New Microbes New Infect 20: 39-42.

23. Sasmono RT, Perkasa A, Yohan B, Haryanto S, Yudhaputri FA, et _al. (2017) Chikungunya Detection during Dengue Outbreak in Sumatra, Indonesia: Clinical Manifestations and Virological Profile. Am J Trop Med Hyg 97(5): 1393-1398.

24. Thonnon J, Spiegel A, Diallo M, Diallo A, Fontenille D (1999) Chikungunya virus outbreak in Senegal in 1996 and 1997]. Bull Soc Pathol Exot 92(2): 79-82.

\section{Your next submission with Juniper Publishers} will reach you the below assets

- Quality Editorial service

- Swift Peer Review

- Reprints availability

- E-prints Service

- Manuscript Podcast for convenient understanding

- Global attainment for your research

- Manuscript accessibility in different formats

( Pdf, E-pub, Full Text, Audio)

- Unceasing customer service

Track the below URL for one-step submission https://juniperpublishers.com/online-submission.php 